\title{
Assessment of Fiber Quality and Yield Allied Parameters under Drought Condition in Cotton
}

\author{
Bonde Shilpa $^{1}$, C. N. Chandrasekhar ${ }^{1}$ and Pusadkar Pratik ${ }^{2}$ \\ ${ }^{1}$ Department of Crop Physiology, Tamil Nadu Agricultural University, \\ Coimbatore- 641003, Tamil Nadu, India \\ ${ }^{2}$ Department of Plant Biotechnology, Centre for Plant Molecular Biology and Biotechnology, \\ Tamil Nadu Agricultural University, Coimbatore- 641003, Tamil Nadu, India \\ *Corresponding author
}

\section{A B S T R A C T}

\begin{tabular}{|l|}
\hline K e y w o r d s \\
Cotton, Soil \\
moisture, Stress, \\
Lint and Yield \\
\hline Article Info \\
\hline $\begin{array}{l}\text { Accepted: } \\
10 \text { March } 2020 \\
\text { Available Online: } \\
10 \text { April } 2020\end{array}$ \\
\hline
\end{tabular}

To investigate the water-deficit tolerance, 3 cotton genotypes (Bunny Bt, Pratima and Anjali.) were grown under normal irrigation and water-deficit conditions. Moisture is a key factor affecting growth and yield of Cotton in which stress is the most important factor limiting crop productivity due to adverse effect on fruit production, square/boll shedding and lint yield as well as fiber quality properties of Cotton. If water supply is limited during boll development it could result in significantly lower yields. In this study stress imposed with four watering treatments viz., $100,75,50$ and $25 \%$ of field capacity at squaring stage given to understand effects of water deficit. We have noticed that 2.5 percent fiber length, fiber fineness and bundle strength decreases in inferior direction as reduction of soil moisture levels. Lint yield was generally reduced under water stress because of reduced boll production primarily due to the production of fewer flowers and bolls, but also because of increased rates of boll abortion when the stress is extreme during the reproductive growth stage. The number of bolls, lint per boll also affects while correlations among yield traits were higher in normal irrigation as compared with water stress moisture levels in all three varieties in which comparatively Bunny $B t$ performed better than Pratima and Anjali.

\section{Introduction}

The global climate changes with continuous water scarcity and drought have become an increasing serious concern about limiting crop production worldwide as it significantly limits Cotton growth and production so necessity of water at every stage of crop growth is required. Hence in this regard it is essential to identify tolerant genetic varieties to understand the mechanisms of drought tolerance in cash crops such as Cotton (Hasan et al., 2018).

The available moisture is a key factor affecting growth and yield of Cotton, water stress is the most important factor limiting crop productivity and adversely affects fruit 
production, square as well as boll shedding, lint yield and fiber quality properties in Cotton (El-Zik and Thaxton, 1989; Karademir et al., 2011).

Cotton lint yield is generally reduced because of reduced boll production resulted due to fewer flowers as well as increased boll abortions when the stress is extreme and when it occurs during reproductive growth (Grimes and Yamada, 1982; McMichael and Hesketh, 1982; Turner et al., 1986; Gerik et al., 1996; Pettigrew, 2004a; Pettigrew, 2004b).

It is known that the quality and quantity of the fiber produced in Cotton plant are directly related to water availability during the different phenological phases of development (Akbar et al., 2019). Completely elongated mature Cotton fiber found rich in cellulose. The fiber development attributes may be correlated with a wide range of factors influenced directly or indirectly by drought which finally leads to poor quality fiber.

If their interactions affecting in fiber development are understood, it will illuminate clear view of fiber development under drought and these genotypes could be exploited as genetic resources in breeding programs which aim to improve drought tolerance in cotton (Singh et al., 2018: Sezener et al., 2015).

Water supply limited during boll development can result in significantly lower yields (Radin et al., 1992; Plaut et al., 1992; de Kock et al., 1990). McMichael et al., (1973) observed that if water stress occurs during the first fourteen days after anthesis, young bolls generally abscise.

Therefore, the present study was conduct to evaluate cotton genotypes under both normal and stress conditions to select the best genotype for tolerant water deficit stress.

\section{Materials and Methods}

\section{Experimental set up}

Three cotton varieties (Pratima, Anjali and Bunny $B t$ ) were used in experiment they are arranged in glass house. The experimental materials were subjected to four watering treatments, which include $\mathrm{T}_{1}$ : Control, $\mathrm{T}_{2}: 75$ percent of field capacity, $\mathrm{T}_{3}$ : 50 percent of field capacity and $\mathrm{T}_{4}$ : 25 percent of field capacity with three replications. Gravimetric method of drought imposition was used for pot preparation.

\section{Sowing/planting}

Three seeds per pot were sown initially. After establishment the thinning was done and single healthy plant was maintained per pot. The treatments were imposed after thirty two days of sowing when first squaring observed.

\section{Yield and yield components}

To assess the relationship between various moisture levels and yield components, the following parameters were recorded. The details of the method for estimating each character are indicated below.

\section{Number of bolls per plant}

The number of bolls per plant was recorded in 90 days old Cotton plants from each replication of all the treatments and the mean value was calculated.

\section{Number of seeds per boll}

Number of seeds per boll was recorded from the yield of first picking of the Cotton plants from each replication of all the treatments and the mean value was calculated. 


\section{Weight of lint per boll ( $\left.\mathrm{g} \mathrm{boll}^{-1}\right)$}

The weight of lint from the yield of first picking for each replication of all treatments was estimated and the mean value was determined and expressed in $\mathrm{g} \mathrm{boll}^{-1}$.

\section{Lint yield per plant (g plant ${ }^{-1}$ )}

The lint yield per plant was recorded from each replication of the treatments and the mean value was expressed in $\mathrm{g}_{\text {plant }}{ }^{-1}$.

\section{Fiber quality parameters}

Random lint samples were collected from each entry and given for fiber quality analysis through High Volume Instrument (Uster Model: HVI classic 900) available in the Department of cotton, Tamil Nadu Agricultural University, Coimbatore.

\section{Percent span length (mm)}

The 2.5 percent span length is the fiber length estimated using fibro graph. This is the fiber length representing majority of the fibers and expressed in millimeter.

\section{Fiber fineness (micronaire)}

This is a relative measure of size, diameter and linear density of fibres, which denotes the fineness of fiber. It is denoted as Micronaire value.

\section{Bundle strength (g/tex)}

Bundle strength denotes the strength of fibers. This is also referred as fiber strength or tensile strength, the maximum specific stress that is developed in a tensile test to rupture the fibers. This parameter is expressed in gram per tex.

\section{Results and Discussion}

\section{Number of bolls per plant}

Data on number of boll per plant showed significant difference in number of bolls per plant among treatments but not in varieties and their interactions (Table 1). The highest mean value was found in Bunny $B t$ in control conditions (7.33) where Anjali was showed lowest (6.00). Pratima and Bunny Bt showed the same no of boll per plant a (4.66) at 75 percent of field capacity. At 25 percent of field capacity Pratima and Anjali showed the same no of boll per plant (1.00) and Bunny $B t$ recorded highest (1.33) (Table 1). The number of bolls per plant and lint yield per boll was significantly different among the various yield characters recorded in present study, the treatments showing significant differences due to the effect of reduced moisture levels on these parameters. According to Grimes et al., (1969) there was a positive correlation between the yield and the number of bolls produced.

\section{Number of seeds per boll}

Number of seeds per boll found to differ significantly among treatments and their interactions but not in varieties. The highest means was found in Bunny Bt (29.11) in control condition. Whereas Pratima (29.14) and Anjali (25.33) showed highest at 75 percent field capacity and 50 percent field capacity respectively (Table 1).

\section{Lint yield per boll (g)}

Data on lint yield per boll (Table 1) revealed significant differences among the varieties, treatments but not their interaction. In control, the highest yield was exhibited by variety Bunny Bt (1.22) whereas Anjali (0.64) was exhibited lowest yield. 
When water level was reduced up to 75 percent of field capacity, lowest yield was found in Pratima (0.57) and highest in Bunny Bt (0.92). At 50 percent of field capacity, Pratima was recorded lowest yield (0.50) and Bunny $B t$ was recorded the highest yield (0.73), similarly at 25 percent of field capacity Bunny $B t$ recorded highest value 0.72 and Pratima recorded lowest value (0.40). Lint yield was generally reduced under water stress because of reduced boll production primarily due to the production of fewer flowers and bolls (Abdel-Monaem et al., 2018; Khan et al., 2018).

\section{Lint yield per plant (g)}

Number of seeds per boll and lint weight per boll was significantly differ among the treatments suggesting that different moisture levels affected the yield at single boll level more predominantly than the whole plant. The lint yield per plant was found to be significantly different among varieties, treatments and their interactions. When moisture level was maintained at field capacity Bunny $B t$ (8.89) exhibited highest yield whereas Anjali showed lowest (3.87). The highest yield at 75 percent field capacity was found in Bunny Bt (4.31) and the lowest in Pratima (2.67). At 50 percent field capacity, the highest yield recorded was 1.83, which was found in Pratima and lowest yield was 1.70 which was found in Bunny Bt. At of 25 percent of field capacity Bunny $B t$ showed highest value 0.97 and Pratima showed lowest value 0.40 (Table 1 ).

\section{Percent span length (mm)}

Data on 2.5 percent span length of three cotton varieties under drought stress treatment has been furnished in Table 2. The significant differences in span length were observed among the varieties, treatments and their interactions. At 100 percent field capacity (control), highest span length was observed in Bunny Bt (33.71) and the lowest was in Anjali (27.25). When water level was reduced from 100 percent to 75 percent field capacity, Bunny Bt (30.37) recorded the highest span length compared to Pratima (27.46). At 50 percent field capacity, Bunny $B t$ exhibited an increased span length as 28.35 and Anjali recorded to have lowest as (22.40), same trend was notices at 25 percent field capacity Bunny $B t$ exhibited increased span length (9.10) and Anjali recorded the lowest (7.64) (Table 2).

\section{Bundle strength (g/tex)}

The bundle strength data is presented in Table 2 , which was found to be significant in varieties, treatments and their interactions. Highest value of bundle strength was recorded in Bunny $B t$ (25.33), same as at 75 percent of field capacity (24.28) as well as 50 percent of field capacity (23.41) and 25 percent field capacity (7.86). The lowest values were observed in Anjali at control (20.38), at 75 percent of field capacity (18.17) at 50 percent of field capacity (17.46) and 25 percent field capacity (6.50).

\section{Fiber fineness (micronaire)}

Data on fiber fineness of three cotton varieties under drought stress treatment is furnished in Table 2. At 100 percent field capacity (control), highest fiber fineness was observed in Anjali (4.3) and the lowest was in Bunny $B t$ (2.6). When water level was reduced from 100 percent to 75 percent field capacity, Anjali recorded highest (3.1) whereas Bunny $B t$ and Pratima observed the same fiber fineness(2.7). At 50 percent field capacity Pratima exhibited increased fiber fineness as 2.2 and Anjali recorded to have lowest (2.0). At 25 percent field capacity Bunny $B t$ exhibited increased fiber fineness as (0.25) and Anjali was recorded the lowest (0.11). 
Table.1 Effect of various moisture levels on number of Bolls, seed per boll, lint per boll (g) and lint yield per plant

\begin{tabular}{|c|c|c|c|c|c|c|c|c|c|c|c|c|c|c|}
\hline \multicolumn{6}{|c|}{ Number of Bolls } & \multicolumn{5}{|c|}{ seed per boll } & \multicolumn{4}{|c|}{ Lint per boll (g) } \\
\hline & Control & $\begin{array}{l}75 \% \\
\text { FC }\end{array}$ & $\begin{array}{l}\mathbf{5 0 \%} \\
\text { FC }\end{array}$ & $\begin{array}{l}25 \% \\
\text { FC }\end{array}$ & Mean & Control & $\begin{array}{l}75 \% \\
\text { FC }\end{array}$ & $\begin{array}{l}\mathbf{5 0 \%} \\
\text { FC }\end{array}$ & $\begin{array}{l}25 \% \\
\text { FC }\end{array}$ & Mean & $\begin{array}{l}75 \% \\
\text { FC }\end{array}$ & $\begin{array}{l}\mathbf{5 0 \%} \\
\text { FC }\end{array}$ & $\begin{array}{l}25 \% \\
\text { FC }\end{array}$ & Mean \\
\hline Pratima & 6.66 & 4.66 & 3.66 & 1.00 & 4.00 & 27.40 & 29.14 & 25.01 & 13.08 & 23.66 & 0.57 & 0.50 & 0.4 & 0.61 \\
\hline Anjali & 6.00 & 4.33 & 2.66 & 1.00 & 3.41 & 25.12 & 24.83 & 25.33 & 17.56 & 23.21 & 0.69 & 0.65 & 0.53 & 0.63 \\
\hline Bunny $B t$ & 7.33 & 4.66 & 2.33 & 1.33 & 3.91 & 29.11 & 26.31 & 21.38 & 17.89 & 23.57 & 0.92 & 0.73 & 0.72 & 0.90 \\
\hline \multirow[t]{2}{*}{ Mean } & 6.66 & 4.55 & 2.77 & 1.11 & 3.77 & 27.21 & 26.76 & 23.91 & 16.18 & 23.51 & 0.73 & 0.62 & 0.55 & 0.71 \\
\hline & \multicolumn{2}{|l|}{$\mathrm{V}$} & $\mathrm{T}$ & \multicolumn{2}{|l|}{ V XT } & \multicolumn{2}{|l|}{$\mathrm{V}$} & $\mathrm{T}$ & \multicolumn{2}{|l|}{ V XT } & $\mathrm{V}$ & $\mathrm{T}$ & \multicolumn{2}{|l|}{ V XT } \\
\hline $\mathrm{SE}(\mathrm{d})$ & \multicolumn{2}{|l|}{0.235} & 0.272 & \multicolumn{2}{|l|}{0.471} & \multicolumn{2}{|l|}{0.809} & 0.934 & \multicolumn{2}{|l|}{1.618} & 0.053 & 0.11 & \multicolumn{2}{|l|}{0.15} \\
\hline $\mathrm{CD}(0.05)$ & \multicolumn{2}{|l|}{0.486} & 0.486 & \multicolumn{2}{|l|}{0.972} & \multicolumn{2}{|l|}{1.67} & 1.929 & \multicolumn{2}{|l|}{3.341} & 0.061 & 0.127 & \multicolumn{2}{|l|}{0.173} \\
\hline $\mathrm{CD}(0.01)$ & \multicolumn{2}{|l|}{0.662} & 0.765 & \multicolumn{2}{|l|}{1.325} & \multicolumn{2}{|l|}{2.276} & 2.628 & \multicolumn{2}{|l|}{4.553} & 0.107 & 0.221 & \multicolumn{2}{|l|}{0.301} \\
\hline
\end{tabular}

\begin{tabular}{|c|c|c|c|c|c|}
\hline & \multicolumn{5}{|c|}{ Lint yield per plant (g) } \\
\hline & Control & $75 \% \mathrm{FC}$ & $50 \% \mathrm{FC}$ & $25 \% \mathrm{FC}$ & Mean \\
\hline Pratima & 6.68 & 2.67 & 1.83 & 0.40 & 2.89 \\
\hline Anjali & 3.87 & 3.03 & 1.77 & 0.53 & 2.30 \\
\hline Bunny $B t$ & 8.89 & 4.31 & 1.70 & 0.97 & 3.97 \\
\hline \multirow[t]{2}{*}{ Mean } & 6.48 & 3.34 & 1.76 & 0.63 & 3.05 \\
\hline & \multicolumn{2}{|r|}{ V } & $\mathrm{T}$ & \multicolumn{2}{|c|}{ V X T } \\
\hline $\mathrm{SE}(\mathrm{d})$ & \multicolumn{2}{|c|}{0.398} & 0.822 & \multicolumn{2}{|c|}{1.120} \\
\hline $\mathrm{CD}(0.05)$ & \multicolumn{2}{|c|}{0.459} & 0.949 & \multicolumn{2}{|c|}{1.293} \\
\hline $\mathrm{CD}(0.01)$ & \multicolumn{2}{|c|}{0.796} & 1.644 & \multicolumn{2}{|c|}{2.240} \\
\hline
\end{tabular}


Table.2 Effect of various moisture levels on 2.5 percent span length, Bundle strength and Fiber fineness

\begin{tabular}{|c|c|c|c|c|c|c|c|c|c|c|c|c|c|c|c|}
\hline & & \multicolumn{4}{|c|}{$\begin{array}{c}2.5 \text { percent span length } \\
(\mathrm{mm})\end{array}$} & \multicolumn{5}{|c|}{ Bundle strength (g/tex) } & \multicolumn{5}{|c|}{$\begin{array}{l}\text { Fibre fineness } \\
\text { (Micronaire) }\end{array}$} \\
\hline & Control & $\begin{array}{c}75 \% \\
\text { FC }\end{array}$ & $\begin{array}{c}50 \% \\
\text { FC }\end{array}$ & $\begin{array}{c}25 \% \\
\text { FC }\end{array}$ & Mean & Control & $\begin{array}{c}75 \% \\
\text { FC }\end{array}$ & $\begin{array}{c}50 \% \\
\text { FC }\end{array}$ & $\begin{array}{c}25 \% \\
\text { FC }\end{array}$ & Mean & Control & $\begin{array}{c}75 \% \\
\text { FC }\end{array}$ & $\begin{array}{c}50 \% \\
\text { FC }\end{array}$ & $\begin{array}{c}25 \% \\
\text { FC }\end{array}$ & Mean \\
\hline Pratima & 30.45 & 27.46 & 25.26 & 8.45 & 20.79 & 23.46 & 22.16 & 21.45 & 7.5 & 16.77 & 3.0 & 2.7 & 2.2 & 0.16 & 1.98 \\
\hline Anjali & 27.25 & 25.06 & 22.4 & 7.64 & 18.68 & 20.38 & 18.17 & 17.46 & 6.5 & 14 & 4.3 & 3.1 & 2.0 & 0.11 & 2.38 \\
\hline $\begin{array}{l}\text { Bunny } \\
\text { Bt }\end{array}$ & 33.71 & 30.37 & 28.35 & 9.1 & 23.11 & 25.33 & 24.28 & 23.41 & 7.86 & 18.26 & 2.6 & 2.7 & 2.1 & 0.25 & 1.85 \\
\hline Mean & 30.47 & 27.63 & 25.34 & 8.38 & 20.86 & 23.06 & 21.54 & 20.77 & 7.29 & 16.34 & 3.3 & 2.83 & 2.13 & 0.17 & 2.07 \\
\hline & & V & $\mathrm{T}$ & \multicolumn{2}{|c|}{ VXT } & \multicolumn{2}{|c|}{ V } & $\mathrm{T}$ & \multicolumn{2}{|c|}{ VXT } & & V & $\mathrm{T}$ & \multicolumn{2}{|c|}{ VXT } \\
\hline $\mathrm{SE}(\mathrm{d})$ & & 0.105 & 0.12 & \multicolumn{2}{|c|}{0.209} & \multicolumn{2}{|c|}{0.16} & 0.185 & \multicolumn{2}{|c|}{0.321} & & 0.082 & 0.094 & \multicolumn{2}{|c|}{0.164} \\
\hline $\mathrm{CD}(0.05)$ & & 0.216 & 0.249 & \multicolumn{2}{|c|}{0.432} & \multicolumn{2}{|c|}{0.331} & 0.383 & \multicolumn{2}{|c|}{0.522} & & 0.169 & 0.196 & \multicolumn{2}{|c|}{0.339} \\
\hline $\mathrm{CD}(0.01)$ & & 0.294 & 0.432 & \multicolumn{2}{|c|}{0.589} & \multicolumn{2}{|c|}{0.321} & 0.663 & \multicolumn{2}{|c|}{0.904} & & 0.231 & 0.267 & \multicolumn{2}{|c|}{0.462} \\
\hline
\end{tabular}


The results were significantly differing in varieties, treatment and their interactions. Effect of various moisture levels on number of bolls, seed per boll, lint per boll and lint per plant was studied in which reduction was observed at different watering conditions. The 2.5 percent span lengths, bundle strength and fiber fineness (Micronaire) were studied to find out effect of water stress on fiber quality which found to be reduced at reduction of soil moisture level. The discussion and result presented above has led to conclusion that when a cotton plant experiences reduced soil moisture levels at the onset of squaring period various physiological and morphological changes occur in the plant which may finally results in yield reduction.

\section{Acknowledgment}

We are grateful to Department of Crop Physiology, Tamil Nadu Agricultural University, Coimbatore for providing financial support and laboratory facilities to carry out this research work.

\section{References}

Abdel-Monaem, M.A., Ghoneima, M.H., ELMansy, Y.M. and EL-Shazly, M.W., 2018.Evaluation of some Genotypes under Water Stress for some Yield and Fiber Quality Properties in Cotton (Gossypium barbadense L.). Journal of Plant Production, 9(5), pp.477-483.

Akbar, M. and Hussain, S.B., 2019. Physiological traits coupled with water deficit tolerance by using multivariate analysis in cotton genotypest. $J$ Genet MolBiol, 3(2), pp.1-11.

De Kock, J., De Bruyn, L.P. and Human, J.J., 1990. The relative sensitivity to plant water stress during the reproductive phase of upland cotton (Gossypium hirsutum L.). Irrigation science, 11(4), pp.239-244.
El-Zik, K. M and P. M. Thaxton. 1989. Genetic improvement for resistance to pests and stresses in cotton. In: integrated pest management systems and cotton production. John Wiley and Sons. New York, USA. pp 191-224.

Gerik, T.J., Faver, K.L., Thaxton, P.M. and El-Zik, K.M., 1996. Late season water stress in cotton: I. Plant growth, water use, and yield. Crop science, 36(4), pp.914-921.

Grimes, D.W. and Yamada, H., 1982.Relation of Cotton Growth and Yield to Minimum Leaf Water Potential 1. Crop Science, 22(1), pp.134-139.

Grimes, D.W., Yamada, H. and Dickens, W.L., 1969.Functions for Cotton (Gossypium hirsutum L.) Production from Irrigation and Nitrogen Fertilization Variables: I. Yield and Evapotranspiration 1. Agronomy Journal, 61(5), pp.769-773.

Hasan, M.M.U., Ma, F., Prodhan, Z.H., Li, F., Shen, H., Chen, Y. and Wang, X., 2018. Molecular and physio-biochemical characterization of cotton species for assessing drought stress tolerance. International journal of molecular sciences, 19(9), p.2636.

Karademir, C., Karademir, E., Ekinci, R. and Berekatoğlu, K., 2011. Yield and fiber quality properties of cotton (Gossypiumhirsutum L.) under water stress and non-stress conditions. African Journal of Biotechnology, 10(59), pp.12575-12583.

Khan, A., Pan, X., Najeeb, U., Tan, D.K.Y., Fahad, S., Zahoor, R. and Luo, H., 2018.Coping with drought: stress and adaptive mechanisms, and management through cultural and molecular alternatives in cotton as vital constituents for plant stress resilience and fitness. Biological research, 51(1), p.47.

McMichael, B.L. and Hesketh, J.D., 
1982.Field investigations of the response of cotton to water deficits. Field Crops Research, 5, pp.319-333.

McMichael, B.L., Jordan, W.R. and Powell, R.D., 1973. Abscission Processes in Cotton: Induction by Plant Water Deficit 1. Agronomy Journal, 65(2), pp.202-204.

Pettigrew, W.T., 2004. Moisture deficit effects on cotton lint yield, yield components, and boll distribution. Agronomy Journal, 96(2), pp.377-383.

Pettigrew, W.T., 2004. Physiological consequences of moisture deficit stress in cotton. Crop Science, 44(4), pp.12651272.

Plaut, Z., Ben-Hur, M. and Meiri, A., 1992. Yield and vegetative growth as related to plant water potential of cotton irrigated with a moving sprinkler system at different frequencies and wetting depths. Irrigation Science, 13(1), pp.39-44.

Radin, J.W., Reaves, L.L., Mauney, J.R. and
French, O.F., 1992. Yield enhancement in cotton by frequent irrigations during fruiting. Agronomy Journal, 84(4), pp.551-557.

Sezener, V., Basal, H., Peynircioglu, C., Gurbuz, T. and Kizilkaya, K., 2015.Screening of cotton cultivars for drought tolerance under field condition. Turkish Journal of Field Crops, 20(2), pp.223-232.

Singh, K., Wijewardana, C., Gajanayake, B., Lokhande, S., Wallace, T., Jones, D. and Reddy, K.R., 2018.Genotypic variability among cotton cultivars for heat and drought tolerance using reproductive and physiological traits. Euphytica, 214(3), p.57.

Turner, N.C., Hearn, A.B., Begg, J.E. and Constable, G.A., 1986. Cotton (Gossypium hirsutum L.): Physiological and morphological responses to water deficits and their relationship to yield. Field Crops Research, 14, pp.153-170.

\section{How to cite this article:}

Bonde Shilpa, C. N. Chandrasekhar and Pusadkar Pratik. 2020. Assessment of Fiber Quality and Yield Allied Parameters under Drought Condition in Cotton. Int.J.Curr.Microbiol.App.Sci. 9(04): 1237-1244. doi: https://doi.org/10.20546/ijcmas.2020.904.146 